\title{
A PRÁTICA DA EVIDENCIAÇÃO DE INFORMAÇÕES AVANÇADAS E NÃO OBRIGATÓRIAS NAS DEMONSTRAÇÕES CONTÁBEIS DAS EMPRESAS BRASILEIRAS*
}

\author{
VERA MARIA RODRIGUES PONTE \\ Professora Doutora do Mestrado em Administração da Universidade de Fortaleza - CE \\ E-mail:vponte@fortalnet.com.br
}

\section{MARCELLE COLARES OLIVEIRA}

Profa. Dra. da Universidade Federal do Ceará

Profa. Dra. do Mestrado Profissional em Negócios Internacionais da Universidade de Fortaleza - CE

E-mail: marcellecolares@fortalnet.com.br

\section{RESUMO}

Para garantir a qualidade das informações disponibilizadas pelas empresas brasileiras, o legislador e os órgãos de regulamentação têm empreendido esforços no sentido de definir as informações que devem ser apresentadas nas demonstrações contábeis. Entretanto, nem todas as orientações têm caráter de obrigatoriedade, tornando-se mais uma questão de ética e responsabilidade corporativa. O presente estudo procura responder à seguinte questão de pesquisa: Qual o grau de observância às orientações sobre evidenciação contábil praticado pelas sociedades anônimas brasileiras no tocante à prestação de informações não contempladas nas demonstrações contábeis tradicionais, consideradas de natureza avançada e não obrigatória? O estudo analisou as demonstrações contábeis de 95 empresas, relativas ao exercício social encerrado em 31/12/2002, com a utilização do método de "análise de conteúdo". Utilizou-se o software Statistical Package for Social Sciences - SPSS para apoio na tabulação e análise dos dados. De um total de 21 itens de evidenciação investigados, apenas seis apresentaram um índice de observância superior a 50\%, o que demonstra que as organizações ainda têm um longo caminho a percorrer na busca da transparência e qualidade na divulgação das informações contábeis.

Palavras-Chave: Evidenciação, Informações Contábeis, Sociedades Anônimas

\section{ABSTRACT}

In order to ensure the quality of information issued by Brazilian enterprises, legislators and regulatory agencies are making efforts to determine the set of information that should appear in the financial statements. However, not all of their recommendations are obligatory, turning this into a matter of company ethics and corporate responsibility. In this paper, the authors attempt to answer the following question: To what extent do Brazilian corporations follow the recommendations on advanced and non-obligatory information disclosure, which is not considered in traditional financial statements. Using the content analysis technique, we studied 95 companies' financial statements for the fiscal year ended 12/31/2002. The Statistical Package for Social Sciences (SPSS) was used for data processing and analysis. We observed that only six out of twenty-one disclosure items under analysis were observed by more than 50\%, which indicates that the Brazilian enterprises still have a long way to go regarding transparency and quality in the disclosure of their accounting information.

Keywords: Disclosure, Accounting Information, Corporations. 


\section{INTRODUÇÃO}

Em todo o mundo, muito se tem discutido sobre a transparência e a qualidade na divulgação das informações contábeis necessárias à consecução do objetivo da Contabilidade, que, segundo ludícibus e Marion (1999, p.53), consiste em "(...) fornecer informação estruturada de natureza econômica, financeira e, subsidiariamente, física, de produtividade e social, aos usuários internos e externos à entidade". Esse conceito assemelha-se ao objetivo da Contabilidade citado na Deliberação CVM n.ำ 29, de 05.02.1986.

De acordo com o Conselho Federal de Contabilidade (CFC), Resolução n.․74, de 16.12.1994, item 1.4, a Contabilidade tem por objetivo:

(...) prover os usuários com informações sobre aspectos de naturezas econômica, financeira e física do patrimônio da entidade e suas mutações, o que compreende registros, demonstrações, análises, diagnósticos e prognósticos, expressos sob a forma de relatos, pareceres, tabelas, planilhas e outros meios.

Para ludícibus (1997, p.20), o objetivo da Contabilidade praticamente permaneceu inalterado ao longo dos anos; as mudanças substanciais verificaram-se nos tipos de usuário e nas formas de informação que têm sido demandadas. Não resta dúvida que o cumprimento da missão da Contabilidade tornou-se mais difícil de ser alcançado, já que cada usuário deseja um conjunto específico de informações que possam suprir seu modelo decisório.

Os usuários da Contabilidade são segregados em dois grandes grupos: o dos usuários externos e o dos usuários internos. Os usuários externos são todos aqueles que se encontram fora da empresa, como o sócio ou acionista não controlador, os fornecedores de matérias-primas, o Estado, as instituições financeiras supridoras de crédito e os concorrentes.

Como afirma Martin (1987, p.2), geralmente, a demanda de informações contábeis oriundas dos usuários externos diferencia-se bastante daquela gerada pelos usuários internos, seja em relação à natureza dos dados, seja no tocante ao nível de agregação, à precisão ou à freqüência.

Sendo assim, "o tratamento dos dados precisa ser diferenciado conforme o usuário, bem como precisam ser diferentes os diversos relatórios, em termos quer de sua forma, quer de seu conteúdo" (MARTINS, 1991, p.337).

Em função dos interesses tão específicos desses grupos de usuários, atualmente a Contabilidade divide-se em dois grandes ramos: Contabilidade Gerencial e Contabilidade Financeira.

Procurando delimitar o campo de atuação de cada uma, Horngren, Foster e Datar (2000, p. 2) afirmam:

A Contabilidade Gerencial mensura e relata informações financeiras, bem como outros tipos de informação que ajudam os gerentes a atingir as metas da organização. (...) A Contabilidade Financeira concentra-se nos demonstrativos dirigidos ao público externo, que são guiados pelos Princípios Contábeis Geralmente Aceitos.

(...)

A Contabilidade Financeira, conforme mencionado, está limitada pelos Princípios Contábeis Geralmente Aceitos. Esses princípios restringem as regras de reconhecimento da receita $e$ mensuração de custo e também os tipos de item que são classificados como ativo, passivo ou patrimônio líquido no Balanço Patrimonial. Ao contrário, a Contabilidade Gerencial não está restrita àqueles princípios contábeis.

Com o objetivo de atender às necessidades dos usuários externos, a Lei n.ำ 6.404, de 15.12.1976, conhecida como Lei das Sociedades por Ações ou Lei das S/A, define um conjunto mínimo de informações que devem ser disponibilizadas pelas organizações de capital aberto. Nesse sentido, a Contabilidade Financeira é responsável por fornecer as demonstrações contábeis tradicionais - Balanço Patrimonial, Demonstração do Resultado do Exercício, Demonstração de Lucros ou Prejuízos Acumulados ou Demonstração das Mutações do Patrimônio Líquido e Demonstração das Origens e Aplicações de Recursos - e informações suplementares através do Relatório da Administração e das Notas Explicativas.

Sabe-se que a forma pela qual uma empresa comunica o seu desempenho aos usuários externos - 
mediante demonstrações contábeis - pode determinar o seu sucesso ou fracasso ao buscar recursos junto aos acionistas, investidores e credores, e principalmente junto ao Governo. Ocorre que as informações divulgadas nas demonstrações tradicionais Balanço Patrimonial, Demonstração do Resultado do Exercício, Demonstração de Lucros ou Prejuízos Acumulados ou Demonstração das Mutações do Patrimônio Líquido e Demonstração das Origens e Aplicações de Recursos - parecem não atender às necessidades dos usuários. Daí a evidenciação de informações adicionais através das Notas Explicativas ou do Relatório da Administração.

As empresas podem adotar diferentes formas de evidenciação, mas devem fornecer informações em quantidade e qualidade que atendam às necessidades dos usuários das demonstrações contábeis. "Ocultar informações ou fornecê-las de forma demasiadamente resumida é tão prejudicial quanto fornecer informação em excesso" (IUDíCIBUS, 1997, p. 115).

Para garantir a qualidade das informações disponibilizadas pelas empresas, o legislador e os órgãos de regulamentação têm empreendido esforços no sentido de definir as informações que devem ser apresentadas nas demonstrações contábeis, no Relatório da Administração e nas Notas Explicativas, em particular, das sociedades anônimas.

Entretanto, nem todas as orientações têm caráter de obrigatoriedade, e, por conseqüência, não necessariamente haverá punição em caso de sua nãoobservância por parte das empresas, tornando-se mais uma questão de ética e responsabilidade corporativa na divulgação das informações contábeis consideradas de natureza avançada.

Com base nas orientações específicas desses órgãos e da legislação sobre divulgação de informações contábeis, o presente estudo procura responder à seguinte questão de pesquisa: Qual o grau de observância às orientações sobre evidenciação contábil praticado pelas sociedades anônimas brasileiras no tocante à prestação de informações não contempladas nas demonstrações contábeis tradicionais, consideradas de natureza avançada e não obrigatória?

Partiu-se da hipótese de que, se essas informações têm se mostrado cada vez mais necessárias para subsidiar as decisões dos usuários da Contabilidade, então elas devem estar sendo amplamente divulgadas pelas empresas.
A presente pesquisa tem por objetivo geral verificar se as sociedades anônimas brasileiras estão atendendo às orientações emanadas dos órgãos específicos e da legislação sobre divulgação de informações contábeis não contempladas nas demonstrações contábeis tradicionais, consideradas de natureza avançada, e cuja evidenciação não necessariamente é obrigatória.

Constituem objetivos específicos do trabalho:

a) levantar as orientações emanadas dos órgãos específicos e da legislação brasileira sobre divulgação de informações contábeis não contempladas nas demonstrações tradicionais das sociedades anônimas; e

b) verificar, nas demonstrações contábeis publicadas por amostra de sociedades anônimas, a presença das principais características das informações contábeis de natureza avançada e não obrigatória.

O presente estudo trata-se de uma pesquisa exploratória compreendendo uma investigação bibliográfica, para levantamento das orientações legais e regulamentares específicas sobre divulgação de informações contábeis aplicadas às sociedades anônimas brasileiras, ou seja, revisão da literatura disponível sobre o assunto, bem como uma pesquisa documental, para levantamento e análise das informações constantes das demonstrações contábeis publicadas.

A pesquisa documental foi realizada em quatro etapas, a saber:

a) delimitação do universo e seleção das empresas a serem pesquisadas;

b) coleta das demonstrações contábeis referentes ao exercício social findo em 31.12.2002 publicadas no Jornal Gazeta Mercantil no período de janeiro a março de 2003;

c) análise da observância das orientações identificadas, mediante confrontação de seu teor com os itens divulgados nas demonstrações contábeis coletadas; e

d) tabulação, consolidação e análise dos dados.

Para alcance dos objetivos da pesquisa, o trabaIho foi segmentado em quatro tópicos. No primeiro, trata-se das orientações contidas na Lei das Sociedades por Ações e em Pareceres de Orientação da CVM sobre a divulgação de informações não contempladas nas demonstrações contábeis tradicionais, 
consideradas de natureza avançada e não obrigatória. No segundo, são apresentados os métodos e técnicas relativos à amostragem utilizada e ao tratamento dos dados consubstanciados nas demonstrações contábeis. No terceiro, apresentam-se os resultados da pesquisa documental. No último tópico, são relatadas as conclusões do estudo.

\section{Demonstrações Contábeis Tradicionais e Informações Complementares de Natureza Avançada e Não Obrigatória}

Conforme ressalta ludícibus (1997), a evidenciação constitui compromisso inalienável da Contabilidade com seus usuários e com seus próprios objetivos, e diz respeito à apresentação ordenada de informações quantitativas e qualitativas, propiciando uma base adequada de informações para o usuário.

A evidenciação refere-se a todo o quadro das demonstrações contábeis, e vários são os métodos disponíveis para realização da evidenciação. Nesse sentido, Gonçalves e Ott (2002, p. 3) ressaltam que:

os métodos de divulgação não se resumem apenas às demonstrações contábeis, mas informações relevantes podem ser disseminadas através do Relatório da Administração, em Notas Explicativas, boletins, reuniões com analistas de mercado/acionistas, entre outros.

ludícibus (1997), Hendriksen e Breda (1991) apresentam os seguintes métodos de evidenciação:

a) Forma e apresentação das demonstrações contábeis;

b) Informações entre parênteses;

c) Notas explicativas;

d) Quadros e demonstrações suplementares;

e) Parecer de auditoria; $e$

f) Relatório da diretoria.

Preocupados em garantir o fornecimento de informações contábeis capazes de atender às exigências dos usuários externos, com freqüência os órgãos reguladores da prática contábil têm expedido normas tratando da divulgação das demonstrações contábeis.
O principal método de evidenciação contábil contempla as demonstrações contábeis tradicionais, que interagem com outros métodos de evidenciação. De acordo com o art. 176 da Lei n. ${ }^{\circ}$ 6.404/76, ao fim de cada exercício social, a diretoria deve elaborar, com base na escrituração mercantil da companhia, demonstrações contábeis que exprimam com clareza a situação do patrimônio da sociedade e as mutações ocorridas no período, compreendendo:

a) Balanço Patrimonial;

b) Demonstração do Resultado do Exercício;

c) Demonstração de Lucros ou Prejuízos Acumulados; e

d) Demonstração das Origens e Aplicações de Recursos.

Demonstrações, quadros suplementares e tabelas podem ser utilizados para detalhar e complementar as informações registradas nas demonstrações contábeis, e, geralmente, são incluídos nas Notas Explicativas ou em seção subseqüente.

As Notas Explicativas devem ser utilizadas para descrever práticas contábeis adotadas pela empresa, e, também, para evidenciar efeitos de procedimentos incorretos eventualmente adotados, que, muitas vezes, distorcem as demonstrações contábeis. O objetivo maior é evidenciar a informação de impacto que nem sempre pode ser facilmente identificada no corpo das demonstrações contábeis.

O Relatório da Administração é o instrumento pelo qual os gestores da empresa comunicam-se com o público externo. Por sua natureza eminentemente analítica, permite que a empresa utilize uma linguagem menos técnica, com o objetivo de atingir maior número de usuários.

Segundo o Financial Accounting Standard Board - FASB (apud HENDRIKSEN e BREDA, 1999, p. 881):
O administrador sabe mais sobre o empre- endimento, do que os investidores, credo- res ou certos "estranhos", e pode aumentar a utilidade da informação financeira, identi- ficando certas transações ou certos even- tos e circunstâncias que afetam o negócio, explicando o impacto financeiro.

Em seu artigo 133, a Lei n.. 6.404/76 determina a obrigatoriedade de elaboração e publicação desse relatório, versando sobre os negócios sociais e os 
principais fatos administrativos do exercício findo, devido à importância desse instrumento como método de evidenciação.

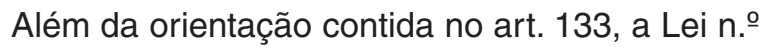
6.404/76 determina a obrigatoriedade de registrar, no Relatório da Administração: a aquisição de debêntures de própria emissão da empresa (art. 55, § 2.ํ); as disposições sobre a política de reinvestimento de lucros e distribuição de dividendos constantes de acordo de acionistas (art. 118, § 5.ㅇ); e a relação dos investimentos em sociedades coligadas e controladas e as modificações ocorridas durante o exercício (art. 243).

A CVM entende que o Relatório da Administração é um elemento poderoso de comunicação entre a companhia, os acionistas e a comunidade em que está inserida, devendo ser redigido com simplicidade de linguagem, para ser acessível ao maior número de pessoas e empresas.

Para ludícibus (1997, p. 114), o Relatório da Diretoria compreende informações de caráter não financeiro que afetam a operação da empresa: expectativas com relação ao futuro, planos de crescimento da companhia e valor de gastos efetuados ou a efetuar no orçamento de capital ou em pesquisa e desenvolvimento.

A CVM manifestou-se acerca do Relatório da Administração em seus Pareceres de Orientação n. ${ }^{\circ} 15 /$ $87,17 / 89$ e 19/90. De acordo com esses pareceres, o relatório deverá conter as informações contempladas na Lei $n . \circ 6.404 / 76$. Entretanto, a título de recomendação e exemplo, a CVM apresenta a relação dos itens que constituem informações que atendem às linhas gerais retrocitadas, já apresentadas por muitas companhias no Brasil (sendo comuns em alguns outros países):

a) descrição dos negócios, produtos e serviços: histórico das vendas físicas dos últimos dois anos e vendas em moeda de poder aquisitivo da data do encerramento do exercício social. Algumas empresas apresentam descrição e análise por segmento ou linha de produto, quando relevantes para a sua compreensão e avaliação;

b) comentários sobre a conjuntura econômica geral: concorrência nos mercados, atos governamentais e outros fatores exógenos relevantes sobre o desempenho da companhia;

c) recursos humanos: número de empregados no término dos dois últimos exercícios e "turnover" nos dois últimos anos, segmentação da mão-de-obra segundo a localização geográfica; nível educacional ou produto; investimento em treinamento; fundos de seguridade e outros planos sociais;

d) investimentos: descrição dos principais investimentos realizados, objetivos, montantes e origens dos recursos alocados;

e) pesquisa e desenvolvimento: descrição sucinta dos projetos, recursos alocados, montantes aplicados e situação dos projetos;

f) novos produtos e serviços: descrição de novos produtos, serviços e expectativas a eles relacionadas;

g) proteção ao meio-ambiente: descrição e objetivos dos investimentos efetuados e montante aplicado;

h) reformulações administrativas: descrição das mudanças administrativas, reorganizações societárias e programas de racionalização;

i) investimentos em controladas e coligadas: indicação dos investimentos efetuados e objetivos das inversões;

j) direitos dos acionistas e dados de mercado: políticas relativas à distribuição de direitos, desdobramentos e agrupamentos; valor patrimonial por ação, negociação e cotação das ações em bolsas de valores;

k) perspectivas e planos para o exercício em curso e os vindouros: poderá ser divulgada a expectativa da administração quanto ao exercício corrente, baseada em premissas e fundamentos explicitamente colocados, sendo que essa informação não se confunde com projeções, por não ser quantificada;

I) em se tratando de companhia de participações, o relatório deve contemplar as informações acima mencionadas, mesmo que de forma mais sintética, relativas às empresas investidas.

O Parecer de Orientação n.. 24/92 da CVM trata dos avanços na qualidade da informação e divulgação das demonstrações contábeis, apoiando e estimulando iniciativas nesse sentido, considerando como exemplos de formas de enriquecimento da informação levada ao público:

a) apresentação de demonstrações complementares, tais como:

- Demonstração do Fluxo de Caixa; 
- Demonstração do Valor Adicionado.

b) apresentação de Notas Explicativas sobre:

- valor de mercado dos estoques, ouro e ações de alta liquidez;

- resultados por linha de produtos ou negócios, em especial referentes às demonstrações consolidadas.

c) outras orientações:

- maior ênfase às demonstrações financeiras consolidadas, de maneira que as demonstrações individualizadas da companhia controladora sejam apresentadas em separado e em menor destaque, contendo as contas e seus respectivos valores exigidos em lei;

- elaboração das demonstrações contábeis consolidadas, mesmo quando os investimentos em controladas não atingirem $30 \%$ do seu patrimônio líquido, conforme previsto no artigo 249 da Lei n.․ 6.404;

- maior ênfase às demonstrações com correção integral, de maneira que aquelas elaboradas na forma societária, quando publicadas, sejam também apresentadas em separado, contendo as contas e valores legalmente exigidos.

Considerando que muitas das citadas orientações da CVM têm caráter facultativo, verifica-se que muitas dessas práticas ficam restritas às companhias que sofrem pressões nesse sentido oriundas do mercado de capitais.

Essa realidade corrobora a afirmação de Choi e Muller (1992) apud Gonçalves e Ott (2002), que apontam quatro categorias de influência na evidenciação praticada pelas companhias: o ambiente em que a empresa está inserida; o mercado de capitais; pressões não financeiras (como os sindicatos); e resposta corporativa às demandas por maior transparência.

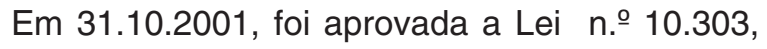
alterando dispositivos das leis n. 6.404 e 6.385, e que traz como principais méritos o fortalecimento da CVM e o aprimoramento das regras de proteção aos direitos dos acionistas minoritários.

A CVM ganhou força no mercado de capitais como órgão fiscalizador e controlador, e, em junho de 2002, criou uma cartilha com recomendações sobre práticas de Governança Corporativa, as quais inclusive se estendem à Contabilidade.

Um dos princípios que regem as práticas de Governança Corporativa é a transparência, que consiste na divulgação precisa e clara das informações pertinentes ao desenvolvimento dos negócios. Essas informações só podem ser apresentadas através de relatórios, os quais deverão satisfazer às necessidades dos interessados e às exigências legais.

A adoção das recomendações da CVM sobre Governança Corporativa comumente significa a utilização de padrões de conduta superiores aos exigidos pela lei, ou pela regulamentação da própria CVM. Por isso, essa cartilha não constitui uma norma cujo descumprimento seja passível de sanção.

A cartilha recomenda que as empresas de pequeno porte, para as quais torna-se elevado o custo de produzir as demonstrações em padrões internacionais, devem ao menos incluir uma demonstração de fluxo de caixa. Transações relevantes que não são obrigatoriamente incluídas nas demonstrações financeiras (off balance-sheet transactions) devem ser detalhadas nas Notas Explicativas.

No tocante às informações contábeis, as recomendações da CVM contidas nessa cartilha dispõem que a empresa deve adotar, além dos princípios de Contabilidade em vigor no Brasil, normas internacionais de Contabilidade promulgadas pelo International Accounting Standards Board (IASB) ou utilizadas nos Estados Unidos (United States Generally Accepted Accounting Principles - US GAAP), examinadas por auditor independente.

Iniciativas voltadas para a adoção das normas internacionais de Contabilidade promulgadas pelo IASB são as grandes mudanças, na matéria contábil, na Lei n. 6.404 , propostas no Projeto de Lei n.ㅇ 3.741/ 2000 de autoria do Poder Executivo, cujo relator é o deputado Émerson Kapaz.

As alterações propostas no projeto de lei têm como arcabouço teórico básico as recomendações do IASB, órgão que congrega as entidades profissionais de Contabilidade de quase todos os países, inclusive o Brasil, dentre as quais se mencionem a substituição da Demonstração das Origens e Aplicações de Recursos pela Demonstração de Fluxo de Caixa e a obrigatoriedade de elaboração da Demonstração do Valor Adicionado.

A primeira versão do projeto de lei previa, também, que as demonstrações contábeis seriam complementadas por informações de natureza social. A menção a esse tipo de informação caracterizava-se como um primeiro passo no sentido da 
obrigatoriedade de elaboração e divulgação do Balanço Social, peça contábil já divulgada em países como França, Portugal, por força de legislação. Entretanto, na versão atual, não há qualquer menção sobre o assunto, embora no Brasil as empresas já publiquem o Balanço Social desde 1999, em Porto Alegre, por força da Lei $n . \circ 8.118 / 1998$, e desde 2001 , no Rio Grande do Sul, por força da Lei $n .011 .440 / 2000$.

\section{METODOLOGIA DA PESQUISA}

No contexto atual, de um mundo sem fronteiras, e com operações cada vez mais sofisticadas, as demonstrações contábeis empresariais passam a ser alvo de interesse de organismos governamentais e não governamentais, nacionais, regionais e internacionais, com vistas ao estabelecimento de padrões adequados de evidenciação.

Das sociedades por ações, espera-se um nível de evidenciação mais depurado do que nos demais tipos societários, em face da legislação específica (Lei n. ㅇ 6.404/76), que aborda, dentre outros, aspectos referentes à evidenciação contábil; às orientações da CVM que se aplicam às sociedades anônimas; e às orientações de órgãos como o Banco Central, a Secretaria Nacional de Previdência Complementar e a Superintendência de Seguros Privados, reguladores das atividades de entidades de segmentos específicos da economia, que dispõem sobre normas e procedimentos contábeis próprios dessas entidades.

Esta pesquisa objetiva avaliar o grau de observância das sociedades anônimas às orientações da CVM e da Lei $n .{ }^{\circ} 6.404 / 76$ sobre divulgação de informações contábeis não contempladas nas demonstrações contábeis tradicionais. O parâmetro para análise das demonstrações contábeis pesquisadas são as informações consideradas de natureza avançada e não obrigatória, conforme referencial teórico, e que fazem parte do Relatório da Administração e das Notas Explicativas.

Sendo assim, na primeira etapa de desenvolvimento deste estudo teórico-empírico, buscou-se conhecer as orientações legais e regulamentares específicas sobre divulgação de informações contábeis aplicadas às sociedades anônimas.

A pesquisa bibliográfica permitiu verificar que, apesar do considerável número de obras editadas sobre o assunto, não foi possível encontrar nenhuma abordando especificamente a questão da divulgação de informações consideradas de natureza avançada e não obrigatória, fato que motivou o interesse pela presente investigação sobre o assunto.

Em seguida, deu-se início à pesquisa documental, para levantamento e análise das informações registradas nas demonstrações contábeis publicadas pelas empresas brasileiras. Quanto à composição e dimensionamento da amostra utilizada, trata-se de uma amostra não probabilística acidental, tendo sido analisadas 95 demonstrações contábeis de sociedades anônimas relativas ao exercício social encerrado em 31.12.2002, publicadas na Gazeta Mercantil, no período de janeiro a março de 2003.

A justificativa para a amostragem utilizada está relacionada à abrangência, linha editorial e credibilidade do jornal em que se encontram publicadas as demonstrações contábeis pesquisadas, tratandose, no caso, de periódico com penetração nacional, especializado em matérias relacionadas ao mundo dos negócios, detentor de grande credibilidade, com bastante utilidade em diversos segmentos. Portanto, com os dados colhidos e analisados, foi possível retratar a evidenciação contábil das sociedades anônimas segundo os parâmetros escolhidos, embora não se possa generalizar as constatações para esse universo de empresas.

As informações contidas nas demonstrações coletadas foram submetidas à análise de conteúdo (content analysis), para identificação do grau de observância das orientações emanadas dos órgãos específicos e da legislação sobre divulgação de informações contábeis de natureza avançada e não obrigatória. Nessa fase da pesquisa, procedeu-se à leitura completa das demonstrações, sendo construído um quadro geral, identificando as evidenciações praticadas pelas empresas integrantes da amostra.

Com essa análise preliminar, foi possível transformar os dados qualitativos em dados quantitativos passíveis de serem trabalhados no software Statistical Package for Social Sciences - SPSS, versão 10.0. Procurou-se realizar análise qualitativa dos dados, por meio de discussão crítica, além de se recorrer à análise quantitativa, por meio de tabelas de freqüência e gráficos estatísticos. Partindose do confronto do referencial teórico com os dados colhidos, foi também possível elucidar o problema de pesquisa e erigir conclusões. 


\section{Evidenciação nas Demonstrações Contábeis das Empresas Brasileiras de Informações Avançadas e Não Obrigatórias.}

O referencial teórico que serviu de subsídio para a análise das demonstrações contábeis das companhias pesquisadas, no tocante a informações complementares, de natureza avançada e não obrigatória, compreendeu:

a) o conteúdo abordado no Parecer de Orientação da CVM n. $.15 / 87$, à guisa de exemplo dos itens que constituem informações que atendem às exigências da Lei n. ${ }^{\circ}$ 6.404/76 sobre Relatório da Administração;

b) o conteúdo abordado no Parecer de Orientação da CVM n.․ 24/92, à guisa de exemplo dos itens que constituem informações contábeis avançadas; c) o conteúdo da cartilha de governança corporativa e do Projeto de Lei n. ${ }^{\circ} 3.741$, no que se referem à evidenciação de informações adicionais, como projetos sociais, EBITDA (lucro antes dos juros, tributos sobre o lucro, depreciação, amortização e exaustão) e Balanço Social, que se alinham às idéias de transparência sobre informações pertinentes ao desenvolvimento dos negócios.

Com relação às orientações do parecer n.․ $15 / 87$ da CVM, a análise do grau de evidenciação praticado pelas empresas pesquisadas utilizou os seguintes dados:

a) quantidade de empresas pesquisadas que divulgaram os itens contemplados para evidenciação em Relatório da Administração (Tabela 1);

b) quantidade de empresas pesquisadas que divulgaram os itens contemplados para evidenciação em Notas Explicativas (Tabela 2).

Tabela 1 - Comportamento do grupo de empresas pesquisado no tocante à divulgação, no Relatório da Administração, dos itens recomendados no Parecer de Orientação n. 15/87 da CVM

Item de Evidenciação

A) descrição dos negócios, produtos e serviços: histórico das vendas físicas dos últimos dois anos e vendas em moeda corrente da data do encerramento do exercício social.

B) comentários sobre a conjuntura econômica geral: concorrência nos mercados, atos governamentais e outros fatores exógenos relevantes sobre o desempenho da companhia. C) recursos humanos: número de empregados no término dos dois últimos exercícios e turnover nos dois últimos anos, segmentação da mão-de-obra segundo a localização geográfica; nível educacional ou produto; investimento em treinamento; fundos de seguridade e outros planos sociais.

D) investimentos: descrição dos principais investimentos realizados, objetivos, montantes e origens dos recursos alocados.

E) pesquisa e desenvolvimento: descrição sucinta dos projetos, recursos alocados, montantes aplicados e situação dos projetos.

F) novos produtos e serviços: descrição de novos produtos, serviços e expectativas a eles relacionadas.

G) proteção ao meio-ambiente: descrição e objetivo dos investimentos efetuados e montante aplicado.

H) reformulações administrativas: descrição das mudanças administrativas, reorganizações societárias e programas de racionalização.

I) investimentos em controladas e coligadas: indicação dos investimentos efetuados e objetivos pretendidos com as inversões.

J) direitos dos acionistas e dados de mercado: políticas relativas à distribuição de direitos, desdobramentos e grupamentos; valor patrimonial por ação, negociação e cotação das ações em bolsas de valores.

K) perspectivas e planos para o exercício em curso e os futuros: poderá ser divulgada a expectativa da administração quanto ao exercício corrente, baseada em premissas e fundamentos explicitamente formulados, sendo que essa informação não se confunde com projeções, por não ser quantificada.

\section{N.. de empresas \\ que divulgaram}

54

48

46

48 Percentual de empresas que divulgaram 
A análise da evidenciação, no Relatório da Administração, dos itens recomendados pelo Parecer de Orientação n. 9 15/87 da CVM, foi sintetizada em quatro classes, levando-se em consideração as faixas de evidenciação:

- Itens divulgados por $\mathbf{1 0 0} \%$ a $\mathbf{7 6} \%$ das empresas: nenhum;

- Itens divulgados por $\mathbf{7 5 \%}$ a $\mathbf{5 1 \%}$ das empresas: três $(A, B, D)$;

- Itens divulgados por $\mathbf{5 0 \%}$ a $\mathbf{2 6 \%}$ das empresas: sete (C, F, G, H, I, J, K);

- Itens divulgados por $25 \%$ a $1 \%$ das empresas: um (E).

Para fins de análise, considerou-se apenas se as empresas evidenciaram ou não, dada a impossibilidade de assegurar sobre a não-evidenciação por não-ocorrência do evento em referência, ou nãoobservância da recomendação da CVM.

Embora não haja obrigação de divulgar a nãoocorrência dos itens de evidenciação recomendados, à exceção dos itens D, E, F, G, H e I, as empresas sempre terão informações a evidenciar acerca dos demais itens.

Os itens na faixa de maior freqüência de evidenciação, de $75 \%$ a $51 \%$, dizem respeito à descrição dos negócios, produtos e serviços, à conjuntura econômica e a investimentos realizados.

Com relação ao item sobre direitos dos acionistas, causa estranheza situar-se na faixa de $50 \%$ a $26 \%$ de divulgação, pois a evidenciação da política de reinvestimento de lucros e distribuição de dividendos com base em acordo de acionistas diz respeito à exigência expressamente contida na Lei n. $\circ 6.404 / 76$, art.118, § 5.․

Também causa estranheza que a evidenciação de informações sobre recursos humanos e perspectivas e planos para o exercício em curso e os futuros situe-se na faixa de $50 \%$ a $26 \%$ de divulgação, pois toda empresa deveria interessar-se em prestar essas informações ao público em geral. A justificativa para o baixo índice de divulgação dessas informações encontra-se, talvez, na nãoobrigatoriedade expressa de sua evidenciação, sendo simples recomendação da CVM.

Pesquisa e desenvolvimento; novos produtos e serviços; proteção ao meio-ambiente e reformulações administrativas recaem naqueles itens cuja não-evidenciação pode dever-se a sua não-ocorrência ou divulgação em Notas Explicativas.

No próprio Parecer de Orientação n.ำ 15/87, da CVM, há menção ao fato de que muitas empresas apresentam o Relatório da Administração em texto sucinto, utilizando-o para as mais variadas justificativas, inclusive a de que os informes necessários para análise dos aspectos em questão já estão contidos nas Notas Explicativas.

No Parecer de Orientação n.ำ 15/87, a CVM manifesta-se contrária a tal procedimento, acusandoo de ilegal e de acarretar perda informacional ao público investidor, aos clientes, aos fornecedores e aos credores.

Para contribuir com as análises, investigou-se a formação do capital das empresas cujas demonstrações contábeis fizeram parte da amostra. Das 95 demonstrações contábeis pesquisadas, 66 pertencem a sociedades anônimas de capital aberto, e 29 a sociedades anônimas de capital fechado (Gráfico 1).

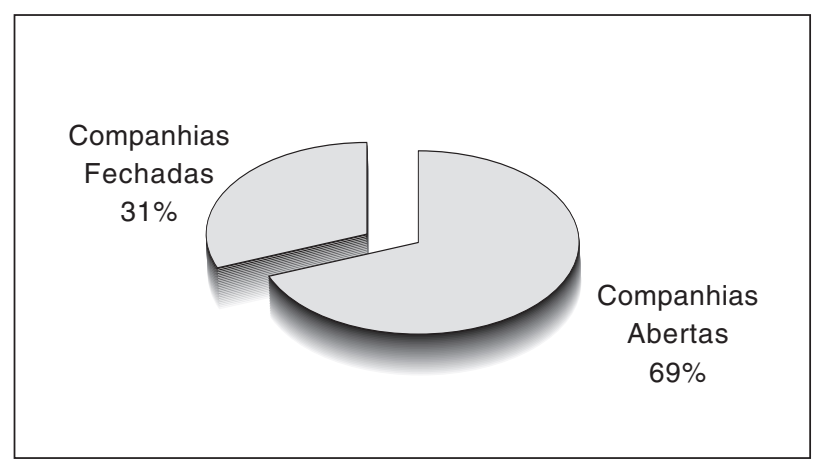

Fonte: Elaborado pelas autoras

\section{Gráfico 1 - Formação do capital das empresas pesquisadas}

Das 95 demonstrações, 17, ou seja, 18\%, não registravam nenhuma menção aos 11 itens sugeri-

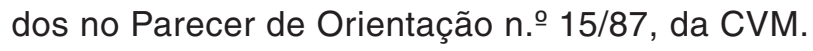
Dessas 17, treze pertencem a sociedades anônimas de capital fechado, e quatro a empresas de capital aberto.

Essa constatação reforça o dado contido no próprio documento da CVM, acerca da não-observância das suas recomendações por parte das sociedades anônimas de capital aberto, bem como 
das exigências contidas na Lei $n . \stackrel{0}{6.404 / 76}$, por parte das sociedades anônimas no país.

Guardando coerência com o critério utilizado para análise acerca da evidenciação, no Relatório da Ad- ministração, dos itens recomendados pelo Parecer de Orientação $n$. $15 / 87$ da CVM, analisou-se a divulgação daqueles itens em Notas Explicativas, conforme Tabela 2.

Tabela 2 - Comportamento do grupo de empresas pesquisado no tocante à divulgação, nas Notas Explicativas, dos itens recomendados para evidenciação no Relatório da Administração, conforme Parecer de Orientação $n .-15 / 87$ da CVM

Item de Evidenciação

A) descrição dos negócios, produtos e serviços: histórico das vendas físicas dos últimos dois anos e vendas em moeda corrente da data do encerramento do exercício social. B) comentários sobre a conjuntura econômica geral: concorrência nos mercados, atos governamentais e outros fatores exógenos relevantes sobre o desempenho da companhia. C) recursos humanos: número de empregados no término dos dois últimos exercícios e turnover nos dois últimos anos, segmentação da mão-de-obra segundo a localização geográfica; nível educacional ou produto; investimento em treinamento; fundos de seguridade e outros planos sociais.

D) investimentos: descrição dos principais investimentos realizados, objetivos, montantes e origens dos recursos alocados.

E) pesquisa e desenvolvimento: descrição sucinta dos projetos, recursos alocados, montantes aplicados e situação dos projetos.

F) novos produtos e serviços: descrição de novos produtos, serviços e expectativas a eles relacionadas.

G) proteção ao meio-ambiente: descrição e objetivo dos investimentos efetuados e montante Aplicado.

H) reformulações administrativas: descrição das mudanças administrativas, reorganizações societárias e programas de racionalização.

I) investimentos em controladas e coligadas: indicação dos investimentos efetuados e objetivos pretendidos com as inversões.

J) direitos dos acionistas e dados de mercado: políticas relativas à distribuição de direitos, desdobramentos e grupamentos; valor patrimonial por ação, negociação e cotação das ações em bolsas de valores.

K) perspectivas e planos para o exercício em curso e os futuros: poderá ser divulgada a expectativa da administração quanto ao exercício corrente, baseada em premissas e fundamentos explicitamente formulados, sendo que essa informação não se confunde com projeções, por não ser quantificada.

Fonte: Elaborado pelas autoras

Levando-se em consideração a faixa de evidenciação, os resultados também foram sintetizados em quatro classes, verificando-se:

- Itens divulgados por $\mathbf{1 0 0 \%}$ a $\mathbf{7 6} \%$ das empresas: um $(A)$;

- Itens divulgados por $\mathbf{7 5 \%}$ a $\mathbf{5 1 \%}$ das empresas: dois (I, J);

- Itens divulgados por $\mathbf{5 0 \%}$ a $\mathbf{2 6 \%}$ das empresas: três (C, D, H);

- Itens divulgados por $\mathbf{2 5 \%}$ a $\mathbf{1 \%}$ das empresas: cinco (B, E, F, G, K).

Observa-se, então, que a evidenciação de alguns itens $(A, I$ e J) ocorre com maior freqüência nas Notas Explicativas. Vale ressaltar que ao apresentar, no todo ou em parte, as informações de evidenciação nas Notas Explicativas, as 
empresas não se eximem de consigná-las onde é legalmente exigido.

Analisou-se, também, o grau de cumprimento das orientações da CVM de forma global, independentemente do local de realização; se no Relatório da Administração ou nas Notas Explicativas (Tabela 3).

A Tabela 3 revela que mesmo não se levando em conta o local da evidenciação, muitas empresas deixam de divulgar informações acerca de assuntos que deveriam ser tratados, como é o caso daqueles relacionados com os itens $\mathrm{A}, \mathrm{B}, \mathrm{C}, \mathrm{J}$ e K. Surpreende que $11 \%$ das empresas pesquisadas simplesmente não tenham feito a descrição dos seus negócios, produtos e serviços.

Com relação à divulgação das informações contábeis avançadas, conforme sugerido no Parecer de Orientação $n .{ }^{\circ}$ 24/92 da CVM, na cartilha de governança corporativa e no Projeto de Reforma da Lei das S/A, verifica-se, ainda, não ser comum essa prática por parte das empresas brasileiras, conforme Tabela 4.

\section{Tabela 3 - Comportamento do grupo de empresas pesquisado no tocante à divulgação dos itens recomendados para evidenciação, conforme Parecer de Orientação n. $015 / 87$ da CVM}

\section{Item de Evidenciação}

\begin{tabular}{c|c} 
N.․ de & $\begin{array}{c}\text { Percentual } \\
\text { empresas } \\
\text { que }\end{array}$ \\
de empresas \\
divulgaram & $\begin{array}{c}\text { que } \\
\text { divulgaram }\end{array}$
\end{tabular}

A) descrição dos negócios, produtos e serviços: histórico das vendas físicas dos últimos dois anos e vendas em moeda corrente da data do encerramento do exercício social.

B) comentários sobre a conjuntura econômica geral: concorrência nos mercados, atos governamentais e outros fatores exógenos relevantes sobre o desempenho da companhia.

C) recursos humanos: número de empregados no término dos dois últimos exercícios e turnover nos dois últimos anos, segmentação da mão-de-obra segundo a localização geográfica; nível educacional ou produto; investimento em treinamento; fundos de seguridade e outros planos sociais.

D) investimentos: descrição dos principais investimentos realizados, objetivos, montantes e origens dos recursos alocados. 62

85

89

54

55 57

57

58

E) pesquisa e desenvolvimento: descrição sucinta dos projetos, recursos alocados, montantes aplicados e situação dos projetos.

F) novos produtos e serviços: descrição de novos produtos, serviços e expectativas a eles relacionadas.

G) proteção ao meio-ambiente: descrição e objetivo dos investimentos efetuados e montante aplicado.

H) reformulações administrativas: descrição das mudanças administrativas, reorganizações societárias e programas de racionalização.

I) investimentos em controladas e coligadas: indicação dos investimentos efetuados e objetivos pretendidos com as inversões.

J) direitos dos acionistas e dados de mercado: políticas relativas à distribuição de direitos, desdobramentos e grupamentos; valor patrimonial por ação, negociação e cotação das ações em bolsas de valores.

K) perspectivas e planos para o exercício em curso e os futuros: poderá ser divulgada a expectativa da administração quanto ao exercício corrente, baseada em premissas e fundamentos explicitamente formulados, sendo que essa informação não se confunde com projeções, por não ser quantificada.

Fonte: Elaborado pelas autoras

A análise da Tabela 4 revela que as empresas dispensam atenção especial à divulgação de seus projetos sociais, tendo sido esse o item que apresentou a maior freqüência de evidenciação, atingindo $44 \%$.
Apesar disso, observa-se que a prática da elaboração e divulgação do Balanço Social ainda é inexpressiva, haja vista que apenas dezesseis empresas o divulgaram junto com suas demonstrações contábeis. 
Tabela 4 - Comportamento do grupo de empresas pesquisado no tocante à divulgação dos itens recomendados para evidenciação, conforme Parecer de Orientação $n$. 24/92 da CVM, Cartilha de Governança Corporativa e anteprojeto de reforma da Lei das S/A

\begin{tabular}{|c|c|c|}
\hline Item de Evidenciação & $\begin{array}{c}\text { N. de } \\
\text { empresas } \\
\text { que } \\
\text { divulgaram }\end{array}$ & $\begin{array}{c}\text { Percentual } \\
\text { de empresas } \\
\text { que } \\
\text { divulgaram }\end{array}$ \\
\hline A) Demonstração de Fluxo de Caixa. & 27 & 28 \\
\hline B) Demonstração do Valor Adicionado. & 26 & 27 \\
\hline C) Notas sobre valor de mercado dos estoques, ouro e ações de alta liquidez. & 29 & 31 \\
\hline $\begin{array}{l}\text { D) Notas sobre resultados por linha de produtos ou negócios, em especial referentes às } \\
\text { demonstrações consolidadas. }\end{array}$ & 26 & 27 \\
\hline $\begin{array}{l}\text { E) Maior ênfase às demonstrações financeiras consolidadas, de maneira que as demonstra- } \\
\text { ções individualizadas da companhia controladora sejam apresentadas num quadro separado, } \\
\text { em menor destaque, contendo as contas e seus respectivos valores exigidos em lei. }\end{array}$ & 33 & 35 \\
\hline $\begin{array}{l}\text { F) Elaboração das demonstrações contábeis consolidadas, mesmo quando os investimentos } \\
\text { em controladas não atingirem } 30 \% \text { do seu patrimônio líquido, conforme previsto no artigo } 249 \\
\text { da Lei } n .{ }^{\circ} 6.404 \text {. }\end{array}$ & 15 & 16 \\
\hline $\begin{array}{l}\text { G) Maior ênfase às demonstrações com correção integral, de maneira que as elaboradas na } \\
\text { forma societária, quando publicadas, sejam também apresentadas em separado, contendo } \\
\text { as contas e valores legalmente exigidos. }\end{array}$ & 3 & 3 \\
\hline H) Projetos sociais. & 42 & 44 \\
\hline I) EBITDA. & 35 & 37 \\
\hline J) Balanço Social. & 16 & 17 \\
\hline
\end{tabular}

Fonte: Elaborado pelas autoras

Surpreende o número de empresas que estão divulgando o EBITDA, num total de 35, apesar de esse modelo de avaliação de empresas venha sendo utilizado há muito pouco tempo. Segundo Martins (1998, p. 3-4):

(...) o que se quer, com o EBITDA, é o valor do caixa, ou melhor, do potencial de geração do caixa (portanto valores antes de se considerarem as depreciações) produzido pelos ativos genuinamente operacionais (excluindo-se, então, as receitas financeiras, que, nesse caso, não constituem o principal objetivo da empresa), sem os efeitos decorrentes da forma de financiamento da empresa (portanto, excluindo-se também as despesas financeiras) e antes dos efeitos dos tributos sobre o resultado (Imposto de Renda e contribuição social sobre o lucro, no caso brasileiro).

Dada a relevância das demonstrações do Fluxo de Caixa e do Valor Adicionado, elas já começam a receber a devida atenção, verificando-se que $28 \%$ e
$27 \%$ das empresas, respectivamente, já as estão divulgando.

Observa-se que apenas 3\% das organizações deram ênfase às demonstrações com correção integral, reflexo da Lei n. 9 9.249, que eliminou a adoção de qualquer sistema de correção monetária de balanço, tanto para fins fiscais quanto para fins societários. Vale destacar que, com essa lei, se assistiu, a partir do exercício de 1996, ao fim de uma prática já consagrada e indispensável para a adequada mensuração do patrimônio e dos resultados das empresas. Como afirmam Ponte e Santos (1998), a extinção da correção monetária representou um retrocesso sem precedentes nas práticas contábeis brasileiras. Foi uma atitude pouco madura e incompatível com o desejo de modernização do Brasil. Dentre as muitas interferências da legislação na Contabilidade, essa foi, sem dúvida, a mais danosa à evolução da ciência contábil no país.

\section{CONCLUSÕES}

Soares (2001) relata a melhoria na qualidade das demonstrações contábeis das empresas brasileiras, por influência do mercado de capitais. Segundo o au- 
tor, as empresas de capital aberto deram nova roupagem a seus balanços depois de negociar ações no mercado norte-americano. Diante do desafio de chamar a atenção do investidor estrangeiro, em meio às variadas opções disponíveis na Bolsa de Nova lorque, algumas companhias trataram de sofisticar os balanços apresentados à CVM, adicionando informações apreciadas pelas boas práticas de relacionamento com o mercado.

Os resultados da presente pesquisa demonstram que as empresas brasileiras em geral ainda têm muito a evoluir no sentido da transparência e qualidade da divulgação das informações contábeis. Fazendose uma análise conjunta dos 21 itens de evidenciação investigados, pode-se, assim, sintetizar os resultados levantados:

- Itens divulgados por $\mathbf{1 0 0 \%}$ a $\mathbf{7 6} \%$ das empresas: um;

- Itens divulgados por $\mathbf{7 5 \%}$ a $\mathbf{5 1 \%}$ das empresas: cinco;

- Itens divulgados por $\mathbf{5 0} \%$ a $\mathbf{2 6} \%$ das empresas: onze;

- Itens divulgados por $25 \%$ a $1 \%$ das empresas: quatro.

Mafra e Ness (2002) realizaram pesquisa enfocando especificamente a qualidade do Relatório da Administração das companhias abertas brasileiras, concluindo que existe um longo caminho a trilhar até que essas peças possam ser consideradas importante elemento de divulgação voluntária das empresas. A presente pesquisa corrobora essa conclusão, verificando-se que muitas empresas têm preferi- do apresentar em Notas Explicativas informações que deveriam constar no Relatório da Administração. A pesquisa de Mafra e Ness (2002) apresentou a conclusão subsidiária de que a análise da conjuntura econômica e de seu impacto sobre os negócios corporativos constitui-se no tema predileto das companhias abertas brasileiras. A presente pesquisa revela que $o$ item de evidenciação mais tratado pelas empresas é aquele referente aos investimentos, ficando em terceiro lugar os comentários sobre a conjuntura econômica.

Apesar de a pesquisa revelar a necessidade de uma maior evolução na transparência e qualidade das demonstrações contábeis, deve-se destacar que outros estudos constatam melhorias ao longo dos anos. É o que demonstra o estudo empreendido pela empresa de consultoria MZ Consult. Comparando os Relatórios da Administração apresentados por $55 \mathrm{com}$ panhias entre 1998 e 2000, a MZ Consult constata evolução nas demonstrações contábeis. A amostra incluiu 54 empresas com programa de ADRs (American Depositary Receipts) e o Banco Itaú. Foram analisados cinco itens, compreendendo o Número de Páginas, Balanço Social/Ambiental, Gestão de Risco, Governança Corporativa e Demonstração do Valor Adicionado.

Destaque-se, por fim, que algumas empresas já reconhecem a importância da apresentação de informações não exigidas pela legislação nas suas demonstrações contábeis como um diferencial competitivo. São companhias que evidenciam a Demonstração do Valor Adicionado, a Demonstração do Fluxo de Caixa, informações sobre trabalhos sociais e preservação do meio-ambiente.

\section{BIBLIOGRAFIAS}

CONSELHO FEDERAL DE CONTABILIDADE. Princípios fundamentais de contabilidade e normas brasileiras de contabilidade. 2ª . ed. Brasília: CFC, 2000.

FIPECAFI. Avaliação de empresas: da mensuração contábil à econômica. São Paulo: Atlas, 2001.

GONÇALVES, Odair; OTT, Ernani. A evidenciação nas companhias brasileiras de capital aberto. In: ENANPAD, 2002; Salvador, p.140.

HENDRIKSEN, Eldon S.; BREDA, Michael F. V. Teoria da contabilidade. Tradução por Antônio Zorato Sanvinente. São Paulo: Atlas, 1999.
. Accounting theory. 5‥ ed., 1991.

HORNGREN Charles T.; FOSTER, George; DATAR, Srikant M. Contabilidade de custos. 9a ${ }^{\text {a }}$ ed. Rio de Janeiro: LTC - Livros Técnicos e Científicos Editora S.A., 2000.

IUDíCIBUS, Sérgio de. Teoria da contabilidade. 5a. ed. São Paulo: Atlas, 1997.

. MARION, José C. Introdução à teoria da contabilidade para o nível de graduação. São Paulo: Atlas, 1999. 
LAKATOS, Eva M.; MARCONI, Marina de A. Técnicas de pesquisa: planejamento e execução de pesquisas, amostragens e técnicas de pesquisa, elaboração, análise e interpretação de dados. 4a․ ed. São Paulo: Atlas, 1999.

MAFRA, Mário A. F.; NESS, Walter L. Jr. O relatório da administração no Brasil: peça de informação ou ficção?. In: ENCONTRO NACIONAL DE PESQUISA EM ADMINISTRAÇÃO, Anais ENANPAD, 2002.

MARTIN, Nilton Cano. Dos fundamentos da informação contábil de controle. 1987. Tese (Doutorado em Controladoria e Contabilidade) - Faculdade de Economia, Administração e Contabilidade da Universidade de São Paulo, São Paulo.
MARTINS, Eliseu. De Luca Pacioli à volta à contabilidade gerencial. Informações Objetivas - Temática Contábil, $n^{\circ} 34, \mathrm{p}$. 335-342, 1991.

MARTINS, Eliseu. EBITDA: o que é isso? IOB, Boletim ํo 06, Temática Contábil, São Paulo, 1998.

PONTE, Vera; SANTOS, Ariovaldo dos. Um novo momento para a contabilidade brasileira. Revista de Contabilidade do CRCSP, ANO II - n. 4, mar. 1998.

SOARES, A. H. Balanços se sofisticaram para atrair investidor estrangeiro. Gazeta Mercantil, São Paulo, 20 de set. 2001.

NOTA:

Endereço das autoras:

Universidade de Fortaleza

Av. Washington Soares, 1321

Fortaleza-CE

60811-905 